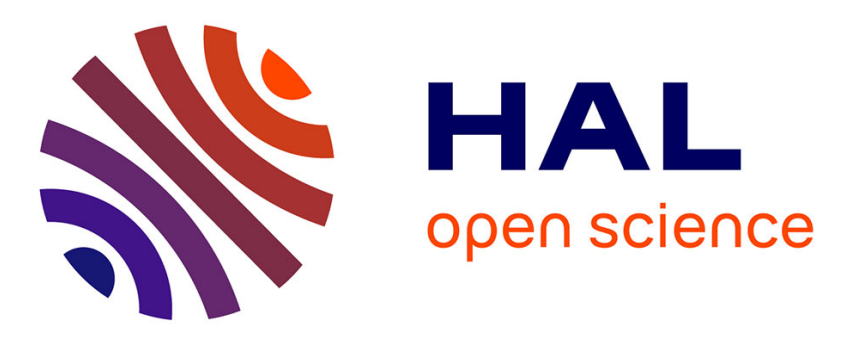

\title{
A New Method for Intra Ocular Pressure in vivo Measurement: First Clinical Trials.
}

Patrick Dubois, Jaouad Zemmouri, Jean François Rouland, Pierre Paul Elena, Renaud Lopes, Philippe Puech

\section{- To cite this version:}

Patrick Dubois, Jaouad Zemmouri, Jean François Rouland, Pierre Paul Elena, Renaud Lopes, et al.. A New Method for Intra Ocular Pressure in vivo Measurement: First Clinical Trials.. Conf Proc IEEE Eng Med Biol Soc, 2007, 1, pp.5762-5. 10.1109/IEMBS.2007.4353656 . inserm-00193030

\section{HAL Id: inserm-00193030 https://www.hal.inserm.fr/inserm-00193030}

Submitted on 30 Nov 2007

HAL is a multi-disciplinary open access archive for the deposit and dissemination of scientific research documents, whether they are published or not. The documents may come from teaching and research institutions in France or abroad, or from public or private research centers.
L'archive ouverte pluridisciplinaire HAL, est destinée au dépôt et à la diffusion de documents scientifiques de niveau recherche, publiés ou non, émanant des établissements d'enseignement et de recherche français ou étrangers, des laboratoires publics ou privés. 


\title{
A New Method for Intra Ocular Pressure in vivo Measurement: First Clinical Trials
}

\author{
Patrick DUBOIS, Member, IEEE, Jaouad ZEMMOURI, Jean François ROULAND, Pierre Paul \\ ELENA, Renaud. LOPES, Philippe PUECH
}

\begin{abstract}
Glaucoma is an ocular disease clinically manifested by an abnormal rise of the Intra Ocular Pressure (IOP) that causes lesions of the optic nerve and can lead to blindness. Ophthalmologists currently use aplanation tonometers whose utilization induces multiple constraints. We propose an investigative method being at one and the same time atraumatic and ambulatory. This original device, taking profit of a physical relation between frequency of mechanical vibration of the ocular globe and IOP, involves vibrometry by laser interferometry and spectral analysis of a mechanical impulse using a temporal micro hammer.

The laser energy delivered to the eye by the device was confirmed to be safe and in full agreement with the authorized security norms. After preliminary in vitro experiments performed using enucleated animal eyes, we made a clinical study on 25 volunteers to evaluate the innocuity and the reliability of this device and to quantify the reproducibility of measurements. All patients declared that discomfort is comparable with that felt during similar tests. Reliability is good and the intra individual reproducibility reveals a high value $(R \geq 0.93)$.

These works will be carried on to check the correlation between the variation of measured values (resonance frequency of the eye-ball) and the variation of reference (IOP) values.
\end{abstract}

\section{INTRODUCTION}

Glaucoma is an ocular disease clinically manifested by an abnormal rise of the Intra Ocular Pressure (IOP) what causes lesions of the optic nerve that can lead to a total blindness. Because of its frequency and its seriousness, glaucoma is one of the first causes of blindness in the adult people of the industrialized countries [1]. It mainly affects the population of 40 years and older and its incidence increases with age. The worldwide population affected by glaucoma was estimated in 2000 at about 67 million. Unfortunately, there is no clinical symptom at the early stage of the disease and when they become noticeable, optic nerve lesions have turned irreversible.

Glaucoma is thus a major concern for public health and

P. Dubois is with the INSERM U 703, Institut de Technologie Médicale, CHRU Lille France (corresponding author phone: +33(0)3.20.44.67.15; fax: +33(0)3.20.44.67.15; e-mail: pdubois@chru-lille.fr).

J. Zemmouri was with Laboratoire de Spectroscopie Hertzienne, USTL, 59655 Villeneuve d'Ascq, France. He is now with Osyris, Lille, France

J.F. Rouland is with the Service d'Ophtalmologie, Hôpital Claude Huriez, CHRU, 59037 Lille 59037, France

P.P. Elena is with Iris-Pharma Society, 06610 La Gaude, France

R. Lopes and P. Puech are with INSERM U 703.

Authors thank OSEO ANVAR for its financial support of this work. requires systematic and mass screenings. Ophthalmologists have several diagnosing tools to detect the glaucoma or to follow-up its evolution, among which the tonometric measurement of the IOP: the IOP in glaucomatous patients differs from that in healthy person (without ocular problem). Increase in IOP is regarded as the main risk factor of glaucoma occurrence. It is thus the most investigated risk factor. The most exact technique for IOP measurement is direct catheterization of the anterior room by a needle connected to a pressure gauge; but due to its invasiveness, it is only carried out on animals for research purposes. The measurement of the IOP by a non-invasive device (tonometer) is called tonometry. It involves the application of a force against the cornea which produces a distortion of the sphere. Many tonometers based on this principle were introduced in clinical routine. Two techniques are commonly used: indentation tonometry and aplanation tonometry [2]. For the latter, measurement must be performed, after corneal anaesthesia, by an ophthalmologist with a slit lamp. The measuring accuracy is of approximately $2 \mathrm{~mm} \mathrm{Hg}$, normal values ranging between 12 and 20mm $\mathrm{Hg}$ [3].

All previously mentioned devices are relatively invasive and require a local anaesthesia of the eye. These techniques require either heavy and expensive means or the presence of an ophthalmologist: all these reasons prevent the repetition of the examinations and a continuous follow-up of the patient. Moreover, they are not free from risks for the patient [4], [5]. The clinicians are therefore on standby of better means of investigation of the IOP. To our knowledge, no device for clinical exploration is currently able to satisfy this waiting. This explains current research [6]-[9]. We designed and achieved a device for indirect IOP measurement, making use of a physical relation between the IOP and the eigen frequencies of mechanical vibration of the ocular sphere [10], [11].

\section{MATERIAL AND METHODS}

\section{A. Device design}

The originality of the method lies in the combined use of three processes:

(a) The relationship existing between mechanical frequency of vibration of the eye and IOP [11]

(b) The vibrometry by laser interferometry with Perrot-

This material is presented to ensure timely dissemination of scholarly and technical work. Copyright and all rights therein are retained by authors or by other copyright holders.

All persons copying this information are expected to adhere to the terms and constraints invoked by each author's copyright. In most cases, these works may not be reposted without the explicit permission of the copyright holder. 
Fabri cavity

(c) The impulse spectral analysis

The combination of these three elements allows:

- A contactless and noninvasive measurement (obtained by (a)), consequently possible without medical intervention.

- A strongly increased simplicity in the optical adjustments required (obtained by (b)).

- A significant reduction of the measurement's duration (obtained by (c))

This [12] led us to investigate a new method: it combines an impulse mechanical excitation with an interferometric optical detection and a spectral analysis of the detected signal. The energy of a low power light source (Fig. 1) is reflected on corneal surface. The vibration of the cornea modulates the signal collected by a photo detector. The spectral analysis of this signal allows quasi instantaneous characterization of the resonance frequencies.

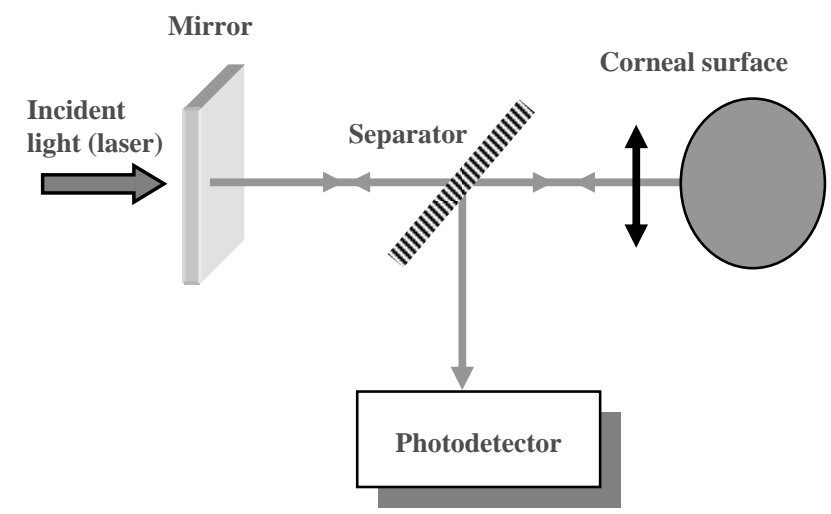

Fig. 1. Principle of the device (Perrot-Fabry cavity)

The light source is a $650 \mathrm{~nm}$ laser diode (RS3a635- $3^{\mathrm{TM}}$, Power Technology Inc $($ ). It is associated to an optical system made up of a convergent lens, two attenuator filters and a semi-reflective mirror. The whole device is held in a tubular case. An aiming crossbar located at the lens focal plan helps the patient keeping optically aligned with the system before laser lighting. We carefully checked that the conditions of use fulfilled the rules being in force [13] concerning direct ocular exposure to the laser radiation: to warrant a non invasive feature, the device must belong to class I laser products "Lasers without danger under all normally foreseeable conditions of use”. As described in section 3 of [13], the acceptable maximum surfacic power density at the top of the cornea is $20 \mu \mathrm{W} / \mathrm{mm}^{2}$ according to the IEC. Measurement made on our beam, under conditions in agreement with the official recommendations, indicates a value of $26.5 \mu \mathrm{W}$. The minimal surface of the section of the beam (at the focusing point) is $2.04 \mathrm{~mm}^{2}$. The surface power density delivered by the device is equal to $13 \mu \mathrm{W} / \mathrm{mm}^{2}$, lower than the acceptable maximum. The emission is discontinuous (impulses of $1 \mathrm{~s}$ maximum). It is thus in addition necessary to precisely examine the value of the radiant energy dispersed by this source to compare it with the acceptable limit of exposure of $30.3 \mathrm{~J} / \mathrm{m}^{2}$. In our case, this value never exceeds $13 \mu \mathrm{J} / \mathrm{m}^{2}$. The class I qualification of the device is thus quite insured.

The electro-optical signal is delivered by an avalanche photodiode (APD C5460 TM, Hamamatsu ${ }^{\circledR}$ ); its case is fitted to the optical system of illumination. This sensor is connected to an electronic interface that ensures a first conditioning of the signal: band-pass $(20-180 \mathrm{~Hz})$ filtering, zeroing the baseline, amplification before sampling and analogical/numerical conversion. The second function of this interface is to synchronize the whole of the measurement procedure: laser diode firing, release of the mechanical stimulation and transmission of the data to a computer. This interface uses a 68HC11 micro controller.

The mechanical system of stimulation consists of a micro electromagnet acting as a micro hammer on the external temporal area (Fig. 2). The impact delivered to the patient is moderate (\# 3N). The operator triggers measurements by means of a pushbutton located on the case of interface: the complete procedure includes the lighting of the laser source during 1 second, followed, after a delay of $50 \mathrm{~ms}$, by the release of the micro hammer and then the data acquisition ( 512 bytes sampled at $512 \mathrm{~Hz}$ ). The fast Fourier transform of the signal is developed under Matlab ${ }^{\mathrm{TM}}$.

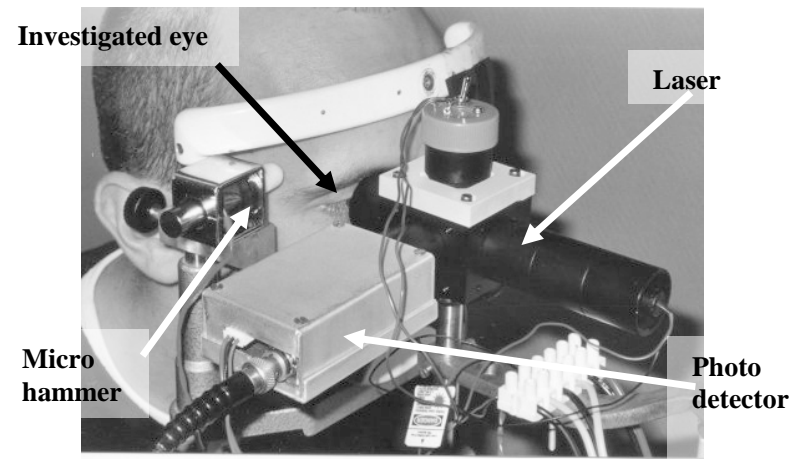

Fig. 2. Photography of the device

Previous in vivo experiments [14] on animals (guinea pigs and rabbits) had led us to confirm our first results obtained in vitro on enucleated pig eyes. We had indeed noticed variations of the resonance frequency accompanying the variations of IOP induced by a bottle infusing a normal saline solution and hanging from a varying height.

\section{B. Clinical study}

This clinical experiment received the agreement (notification CP 13/22) from the CCPPRB (french ethical Consultative Board for Individual Safety in Biomedical Research) commissioned to warrant the full regard for the Helsinki declaration. A notification was made to the CNIL (french National Committee concerned with Informatics and Personal Rights). The patient's consent was systematically obtained before starting the experiments, according to the binding procedure. The objectives of the clinical study, performed at the Clinical Investigation Centre of the CHRU of Lille, were to check the harmlessness of measurements and to evaluate the intra individual reproducibility of measurements. 25 healthy (without glaucoma) subjects were 
included in the study (10 men and 15 women; age ranging between 19 and 43 years; average 26.4 years). The simultaneous measurement of the IOP (by conventional tonometry) and of frequency of resonance were performed every 2 hours, for each patient, between 8 a.m. and 6 p.m. 4 successive frequency measurements were all made on the right eye. 4 additional measurements were made at 8 a.m., with a Valsalva's experiment intended to artificially increase the IOP. 10 measurements (instead of 4) were made at 2 p.m. On the whole, 34 measurements were performed for each subject.

\section{RESULTS}

The obtained curves show a damped oscillatory waveform (Fig. 3). They last between 100 and $200 \mathrm{~ms}$. We retained in our study the 4 peaks of maximum amplitude extracted by spectral analysis of each measurement. We call "main frequency" the one with highest peak.
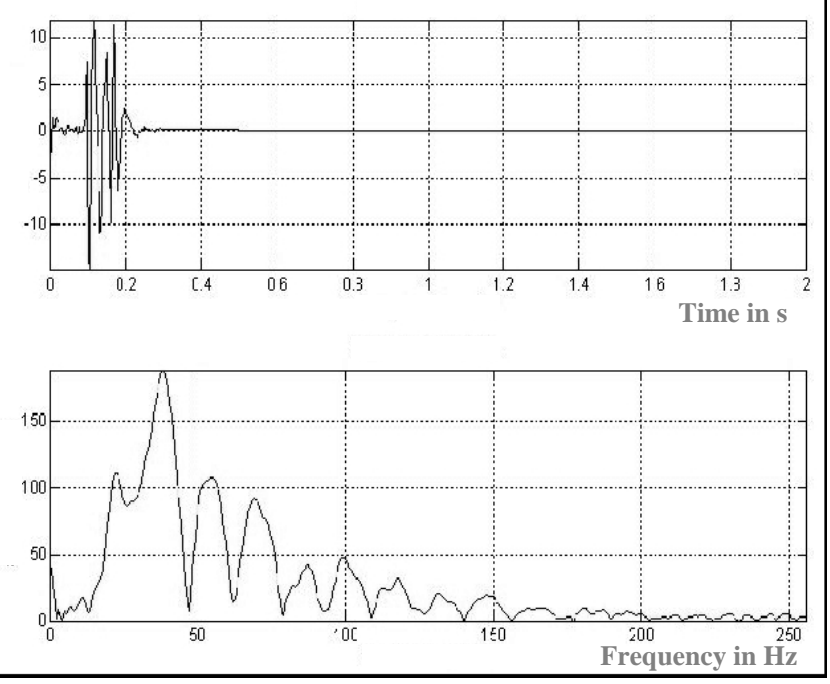

Fig. 3. Example of recorded curves. On the top: a time signal, at the bottom: its corresponding frequency spectrum

\section{A. Tolerance}

The tolerance of measurement was evaluated by both objective and subjective criteria collected by means of a structured questionnaire designed before the beginning of the clinical study. They are expressed as follows:

- Visual acuity: only one subject mentioned a loss of two lines of vision at $(\mathrm{t}+5 \mathrm{mn})$ and $(\mathrm{t}+10 \mathrm{mn})$. This loss disappeared at $(\mathrm{t}+15 \mathrm{mn})$. This reversible spontaneous loss of vision was imputed to the dazzle of the subject which however qualified as "little disturbing" the dazzle of the laser.

- Scotoma related to the post-image: no subject exhibited scotoma at $(\mathrm{t}+5 \mathrm{mn})$.

- Pain related to mechanical stimulation: no subject stated to have felt pain when hammer impacted. Only one patient felt a "moderate discomfort".

- Discomfort caused by the laser illumination: 33\% of the subjects stated not to have been disturbed by illumination,
$66 \%$ were slightly disturbed. A quantitative survey evaluated the level of their embarrassment on a scale ranging from 0 to 100: the mean value was $23.9 \pm 15.6$. As a comparison, this survey was done on the same subjects after their examination with the slit lamp. The mean value was $33.3 \pm 14.7$. The comparison of the averages by a $T$ test of Student (paired series) shows a statistically significant difference between the two examinations $(p<0.05)$ in favor of our device.

- Inspection with the slit lamp: it did not show any abnormality at ( $\mathrm{t}+5 \mathrm{mn})$ and $(\mathrm{t}+15 \mathrm{mn})$.

- Corneal examination with fluoresceïn: 2 specific keratites (diameter 1mm) were detected.

- Fundus examination: no abnormality was observed. The benignity of the observed side-effects allows us to conclude that the tolerance of technique is good. Dazzling seams to be the most frequent side-effect but its tolerance is better than some current ophthalmologic examinations.

\section{B. Failure rate}

Among the 898 recordings, 18\% could not be interpreted, i.e. no calculation of the resonance frequencies performed. The 3 causes of these failures are:

- Presence of multiple and indistinguishable signals (7.8\%): they are mainly consecutive with a blinking reflex of eyelid.

- Absence of signal (6.7\%): they are due either to a device failure (defect of laser lighting or of hammer release) or to an optical misalignment following a movement of the

TABLE I

COEFFICIENTS OF INTRACLASS CORRELATION AT THE MAIN FREQUENCY

\begin{tabular}{cc}
\hline \hline Time of the day & R values \\
\hline 8 a.m. & 0.95 \\
8 a.m. with Valsalva & 0.94 \\
10 a.m. & 0.98 \\
12 a.m. & 0.98 \\
2 p.m. & 0.99 \\
4 p.m. & 0.98 \\
6 p.m. & 0.93
\end{tabular}

patient.

- Saturated signals (3.6\%) related to a fugitive overintensity of the laser.

\section{Reproducibility}

$90 \%$ of measurements had a variation coefficient lower than $10 \%$. The reproducibility was estimated by calculating the coefficients of intraclass correlation. We limited our study to the values at the main frequency. This coefficient measures the correlation between the 4 answers during the same measurements' series for each subject. Reproducibility is regarded as a good one if the coefficient $\mathrm{R}$ is between 0.71 and 0.90 , as a very good one if it exceeds 0.91 .

The obtained results are very satisfactory, since the values always are 0.93 or more (table I). 


\section{CONCLUSION AND PROSPECTS}

This work establishes a first clinical validation of harmlessness and reproducibility of the measurements performed with this device, which is now patented [15]. However, no significant correlation between the variation of the measured frequencies and the variation of the IOP measured by conventional tonometry can be assessed in the frame of an intersubject analysis. We think that too many physical parameters are involved in generating the detected signal to afford the establishment of a standardized range for the human eye and to permit an absolute IOP measurement. It seems rather that the main indication of such a device is for intrasubject's investigations in clinical follow-ups which is the aim of this work. A future clinical study is now scheduled, including glaucomatous volunteer patients for screening more scattered and more varying IOP values.

We also pointed out the some technical and methodological improvements to increase the reliability of this new technique: the use of a split aiming crossbar will help the subject in optical alignment, the reduction by at least a factor 2 of the laser lighting duration. We will also deal with an optimization of the acquisition interface and a miniaturization of the optical parts (by use of optical fibers).

The developed device has a unique feature: the absence of ocular contact makes it possible to consider ambulatory and continuous measurements. This could dramatically change the current techniques for diagnosis, follow-up and screening policies.

\section{REFERENCES}

[1] Quigley H.A, Vitae S. Models of open-angle glaucoma prevalence and incidence in the United States. Invest. Ophthalmol. Vis. Sci. ; 38 : 8391, 1997.

[2] Goldman H, Schmidt T. Über Applanationstonometrie. Acta Ophthalmol., 134 : 221, 1957.

[3] Béchetoille A. Tonométrie d'hier et de demain. Bull. Soc. Ophtalm. Fr. ; 89 (8-9) : 1089-93, 1989.

[4] Smith C.A, Pepose T.S. Disinfection of tonometers and contact lenses in the office setting: are current techniques adequate? Am. J. Ophthalmol., 127(1) : 77-84, Jan 1999.

[5] Maldonado H.J. Corneal epithelial alterations resulting from use of chlorine-disinfected contact tonometer after myopic photorefractive keratectomy. Ophthalmology 1998 Aug.

[6] Hamelink J.N, Cloud G.L., Ocular tonometry through sonic excitation and laser doppler velocimetry, J. Biomech. Eng., Nov; 101:267-70, 1979

[7] Coquart L, Depeursinge C, Curnier A, Ohayon R., A fluid-structure interaction problem in biomechanics : prestressed vibrations of the eye by finite element method, J. Biomechanics ; 25 : 1105-18, 1992.

[8] Alam S.K, Richards D.W, Parker K.J., Detection of intraocular pressure in the eye using sonoelastic doppler ultrasound, Ultrasound in Med. Biol.; 20(8): 751-8, 1994

[9] Drescher J. Stork W., Hey S., Gundlach A., Mueller-Gasser K., Kreiner C., Non contact measurement of intraocular pressure using a modified Michelson interferometer, Proc. of the Eur. Ass. for Vision and Eye Research, Alicante, Spain; p. 104-113, 8-11 oct. 2003

[10] Coquart L., Modélisations mécanique et numérique des vibrations des systèmes couplés fluide-structure, application à un système biomécanique précontraint: l'œil, Thèse de Doctorat, Université Joseph Fourier, Grenoble I, 1990.

[11] Jouve F. Modélisation de l'œil en élasticité non-linéaire. Ed. : Masson, Paris, 1993
[12] P. Dubois, J. Zemmouri, J.-F. Rouland, P. P. Elena, Une nouvelle méthode de mesure de la pression intraoculaire, ITBM-RBM, vol. 26, Issue 4, Pages 285-290, September 2005.

[13] AFNOR. Sécurité des appareils à laser. Partie 1 : classification des matériels, prescriptions et guide de l'utilisateur. NF EN 60825-1 juillet 1994.

[14] Jourdel D., Approche expérimentale d'une mesure de la PIO par méthode interférométrique, D.E.A. G.B.M. Compiègne, Sept 1998

[15] Zemmouri J., Dubois P., Elena P.P., Rouland J.F., Debut A. Method and device for detecting fundamental natural modes of vibration of an eye by laser interferometry and their use for measuring intraocular pressure. International patent pending (09/10/2001) $\mathrm{n}^{\circ}$ PCT/FR01/03108 